\title{
Cumulative ultraviolet radiation flux in adulthood and risk of incident skin cancers in women
}

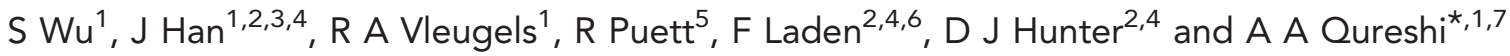

${ }^{1}$ Department of Dermatology, Brigham and Women's Hospital and Harvard Medical School, 45 Francis Street, 221L, Boston, MA 02115, USA; ${ }^{2}$ Channing Division of Network Medicine, Department of Medicine, Brigham and Women's Hospital and Harvard Medical School, Boston, MA 02115, USA; ${ }^{3}$ Department of Epidemiology, Fairbanks School of Public Health, Simon Cancer Center, Indiana University, Indianapolis, IN 46202, USA; ${ }^{4}$ Department of Epidemiology, Harvard School of Public Health, Boston, MA 02115, USA; ${ }^{5}$ Maryland Institute of Applied Environmental Health, College Park, College Park, MD 20742, USA; ${ }^{6}$ Exposure, Epidemiology and Risk Program, Department of Environmental Health, Harvard School of Public Health, Boston, MA 02115, USA and 'Department of Dermatology, Warren Alpert Medical School, Brown University, Providence, RI 02903, USA

Background: Solar ultraviolet (UV) exposure estimated based on residential history has been used as a sun exposure indicator in previous case-control and descriptive studies. However, the associations of cumulative UV exposure based on residential history with different skin cancers, including melanoma, squamous cell carcinoma (SCC), and basal cell carcinoma (BCC), have not been evaluated simultaneously in prospective studies.

Methods: We conducted a cohort study among 108578 women in the Nurses' Health Study (1976-2006) to evaluate the relative risks of skin cancers with cumulative UV flux based on residential history in adulthood.

Results: Risk of SCC and BCC was significantly lower for women in lower quintiles vs the highest quintile of cumulative UV flux (both $P$ for trend $<0.0001$ ). The association between cumulative UV flux and risk of melanoma did not reach statistical significance. However, risk of melanoma appeared to be lower among women in lower quintiles vs the highest quintile of cumulative UV flux in lag analyses with 2-10 years between exposure and outcome. The multivariable-adjusted hazard ratios per $200 \times 10^{-4}$ RobertsonBerger units increase in cumulative UV flux were 0.979 (95\% confidence interval (Cl): 0.933, 1.028) for melanoma, 1.072 (95\% Cl: $1.041,1.103)$ for SCC, and $1.043(95 \% \mathrm{Cl}: 1.034,1.052)$ for BCC.

Conclusions: Associations with cumulative UV exposure in adulthood among women differed for melanoma, SCC, and BCC, suggesting a potential variable role of UV radiation in adulthood in the carcinogenesis of the three major skin cancers.

Ultraviolet (UV) radiation and geographic location previously have been implicated as risk factors for basal cell carcinoma (BCC), squamous cell carcinoma (SCC), and melanoma (Bulliard, 2000; Almahroos and Kurban, 2004; Qureshi et al, 2008). Populations living in geographic locations with latitudes closer to the equator have been reported to have higher rates of BCC and SCC than that in other populations (Suzuki et al, 1996; Leiter and Garbe, 2008). The incidence ratios of BCC:SCC vary by latitude from $3: 1$ to 10:1 (Urbach, 1991). However, SCC appears to be more strongly associated with UV exposure than BCC (Magnus, 1991; Urbach, 1991; English et al, 1998; Ramos et al, 2004); and subjects who receive high UV doses are more likely to develop SCC and have a lower BCC:SCC ratio when compared with those who receive lower UV doses (Ramos et al, 2004). Although there is sufficient evidence suggesting that the spectrum of UV radiation reaching the Earth's surface is involved in the development of melanoma (IARC, 2006), the association between sun exposure and melanoma is very different from that between sun exposure and

*Correspondence: Dr Professor AA Qureshi; E-mail: aqureshi@bics.bwh.harvard.edu

Received 6 November 2013; revised 6 January 2014; accepted 8 January 2014; published online 4 March 2014

(C) 2014 Cancer Research UK. All rights reserved 0007 - 0920/14 
BCC and SCC (Kennedy et al, 2003). Compared with SCC and $\mathrm{BCC}$, melanoma is more likely to be associated with a pattern of intermittent sun exposure rather than continuous sun exposure (Gandini et al, 2005; Landi et al, 2006). For example, a metaanalysis using data from 57 original case-control, cohort or crosssectional studies supports the hypothesis that there is a positive association for intermittent sun exposure and an inverse association for a highly continuous pattern of sun exposure with regard to melanoma risk (Gandini et al, 2005). In contrast, non-melanoma skin cancer, especially SCC, is less likely to be associated with an intermittent pattern of sun exposure (English et al, 1998; Leiter and Garbe, 2008).

Exposure to sunlight, often ascertained by survey questions such as 'time spent outdoors' at various ages, has traditionally been used in case-control studies (English et al, 1998; Kennedy et al, 2003; Iannacone et al, 2012). However, it may be subject to recall bias and misclassification bias. In addition, these measures only account for duration of exposure and do not account for intensity of exposure. As a result, it is difficult to quantify sun exposure using 'time spent outdoors' or similar measures. Other methods (e.g., UV exposure based on residential history) to capture sun exposure have been developed (Fears et al, 2002).

Assessments on UV exposure based on residential history have been used in several previous case-control or descriptive studies to estimate the association between UV exposure and melanoma (Jemal et al, 2000; Fears et al, 2002; Tatalovich et al, 2006). One such measure is the UV index, which is developed by the National Weather Service and the Environmental Protection Agency, to predict UV radiation levels on a scale of 0 to > 11 (Coldiron, 1998; Schmalwieser et al, 2005). This measure accounts for latitude, altitude, cloud cover, haze, time of day, and ozone concentrations (Blunden et al, 2004; Brooks et al, 2005). In our recent study using data from the Nurses' Health Study (NHS) with adjustment for host risk factors, the relative risk of SCC was significantly higher among women who resided in states with medium and high UV indices when compared with women who resided in states with low UV index in early life (birth, ages 15 and 30) (Qureshi et al, 2008). In contrast, the relative risk of BCC was lower than that of SCC, whereas the relative risk of melanoma was not significantly different across the gradient of UV indices $(\leqslant 5,6$, and $\geqslant 7$ ) (Qureshi et al, 2008). However, this study only assessed the associations of skin cancers with sun exposure intensity at three specific time points (at birth, ages 15 and 30) in early life, and did not assess the associations of skin cancers with sustained UV exposure over long durations.

Another surrogate measure to assess cumulative sun exposure that is less influenced by recall bias is UV radiation flux (Scotto et al, 1988, 1996; Jemal et al, 2000; Fears et al, 2002; Tatalovich et al, 2006). Based on residential histories, UV flux is calculated where UV flux units represent radiant energy per unit area and are measured in Robertson-Berger (RB) metre units (Fears et al, 2002). The United States has been considered an ideal model to study the effect of geography on the risk of incident skin cancer given the variation in both UV indices and UV flux across a north-south gradient (Scotto and Fears, 1987; Jemal et al, 2000).

Although data on melanoma are collected in the Surveillance Epidemiology and End Results (SEER) database, no US national registries track either BCC or SCC (Elder, 1995; Boni et al, 2002). For this reason, data on all three types of skin cancers within the same population are difficult to obtain. In this study, we characterise the association between cumulative sun exposure over long durations in adulthood and risks of incident melanoma, SCC, and BCC in the same cohort (NHS) of US women as studied by Qureshi et al (2008). We use cumulative UV flux during the cohort follow-up as a surrogate marker for cumulative sun exposure in adulthood.

\section{MATERIALS AND METHODS}

Study population. The NHS is an ongoing prospective cohort study that was established in 1976 when 121700 female registered nurses completed a mailed questionnaire that included items about risk factors for chronic diseases (Colditz et al, 1986). At enrolment, study participants were $30-55$ years of age and resided in the following 11 states: California, Connecticut, Florida, Maryland, Massachusetts, Michigan, New Jersey, New York, Ohio, Pennsylvania, and Texas. These states were originally chosen based on their size and approval of the study by the respective nursing associations. Since cohort inception, participants now reside in every US state. The cohort has a high follow-up rate up to 96\% (Giovannucci et al, 1995). Institutional human studies research approval was obtained at the Brigham and Women's Hospital. The completion and return of the self-administered questionnaire was considered as informed consent.

Case ascertainment. NHS participants have been asked to report new diagnoses of melanoma (International Classification of Diseases for Oncology third revision (ICD-O-3) code: M8720/3)], SCC (ICD-O-3 code: M8070/3), and BCC (ICD-O-3 code: M8090/3) during the follow-up. Women who reported melanoma or SCC were asked for permission to obtain medical records, which were reviewed by study physicians to confirm melanoma and SCC diagnoses. The confirmation rates for melanoma and SCC reached $93 \%$ and $97 \%$, respectively. SCC in situ and melanoma in situ were excluded from this analysis. Medical records were not obtained for self-report of BCC. However, a high accuracy of self-reported BCC over $90 \%$ has been demonstrated in previous validation studies (Colditz et al, 1986; Hunter et al, 1992).

Estimation of cumulative UV flux. UV flux is an estimate of the amount of UVB radiation (wavelength range $290-315 \mathrm{~nm}$ ) and part of UVA radiation (wavelength range 315-330 $\mathrm{nm}$ ) reaching the earth's surface that is measured by RB metres (Scotto et al, 1988). UV flux takes into account factors that could affect this parameter, such as cloud cover, altitude, and latitude (Scotto et al, 1996). Radiation in the $290-330-\mathrm{nm}$ wavelength range is monitored by a magnesium tungstate sensor and weighted according to an action spectrum that parallels that for skin erythema (Scotto et al, 1988). The RB metre integrates the amounts of UV radiation and provides counts in 'sunburn units' (RB units) (Scotto et al, 1988, 1996). The measured UV flux could have varied according to geographic factors, such as latitude, longitude, and altitude, and physical, or meteorological factors (Scotto et al, 1988). A map showing the gradient of annual UV radiation in RB units across the United States could be found elsewhere (Jemal et al, 2000). An amount of $440 \mathrm{RB}$ units may produce a typical sunburn reaction to untanned Caucasian skin (Scotto et al, 1996). This amount of biologically effective radiation (relative to a wavelength of $297 \mathrm{~nm}$ ) is referred to as the minimal erythema dose and is equivalent to $\sim 25-35 \mathrm{~mJ} \mathrm{~cm}^{-2}$ (DeLuisi and Harris, 1983).

UV flux for each study participant was estimated based on residential history according to detailed methods documented previously (Fears et al, 2002). Briefly, the potential cumulative UV flux that a participant could have received over a period of time was estimated by summing the annual UV flux data over the follow-up (Scotto et al, 1996; Fears et al, 2002). In the present study, residential locations were available for 1976 and 1986-2006 for cohort participants. If the woman lived in the same residence in 1976 as in 1986, we assumed that she lived in the same residence during this period. If the residences in 1976 and 1986 were different, we assumed that in 1978-1980 she lived in the residence as in 1976, and in 1982-1984 she lived in the residence as in 1986 (Arkema et al, 2013). Place of residence during a 2-year 
cycle for each participant was rounded off to the biennial July of each even numbered cycle year. If a participant moved during the cycle, we assumed that she spent the entire cycle (2-year period) at the residence that she indicated at the end of the cycle.

Statistical analysis. The analysis was restricted to Caucasian women who did not have missing data on residence in 1976. Participants contributed person-time from the date of return of the 1976 questionnaire. Accumulation of follow-up time ceased upon the date of the first diagnosis of a cancer, death, or return of the 2006 questionnaire, whichever came first. Women with a baseline history of any cancer before 1976 were excluded from the analysis. We used Cox proportional hazards models stratified by age (categorised in 5-year increments) and follow-up intervals to estimate hazard ratios (HRs) and 95\% confidence intervals (CIs) for incident skin cancers associated with cumulative UV flux. Cumulative UV flux was modelled as a residence and time-varying variable divided into quintiles, and trend tests were performed by assigning median values for these quintiles and treating the new variable as a continuous term in the models. Women in the highest quintile were set as the reference group. For multivariable analyses, covariates relevant to skin cancer risk were included in the models, specifically mole counts on left arm (none, $1-2,3-5$, or $\geqslant 6$ ); hair colour at age 20 years (black, dark brown, light brown, blonde, or red); ability to tan (almost none, little tan, average tan, or deep $\tan$ ); susceptibility to burn (no burn, some redness, burn, painful burn, or painful burn with blisters); lifetime severe sunburn counts (none, $1-2,3-5$, or $\geqslant 6$ ); family history of melanoma (yes or no) (Qureshi et al, 2011); UV indices at state of residence at birth, 15 and 30 years of age $(<5,6$, and $\geqslant 7)$ (Qureshi et al, 2008); physical activity level $(<3.0,3.0-8.9,9.0-17.9,18.0-26.9$, and $\geqslant 27.0$ metabolic equivalents hours per week) (Lee et al, 2009); and rotating night shift (never, 1-9 years, and $\geqslant 10$ years) (Schernhammer et al, 2011). In addition, we fitted adjusted Cox proportional hazards models with cumulative UV flux using restricted cubic splines to examine the shapes of the dose-response relationships between cumulative UV flux and risk of skin cancers (Durrleman and Simon, 1989). Multivariable HRs were estimated for cumulative UV flux levels ranging from 200 to $5400 \times 10^{-4} \mathrm{RB}$ units relative to a reference value of $1680 \times 10^{-4} \mathrm{RB}$ units. Modelling results are shown as graphs of the smoothed splines with $95 \%$ CIs.

Sensitivity analyses were conducted using lag times of 2-10 years between exposure and outcome. For example, incident skin cancers during the 1998-2000 cycle would be matched to cumulative UV flux in 1996 for 2-year lag analysis and matched to cumulative UV flux in 1988 for 10 -year lag analysis. In these sensitivity analyses (i.e., lag analyses), the quintile cut points for cumulative UV flux may be different from those used in the main analyses because of different follow-up years. All data analyses were performed using SAS version 9.1 (SAS Institute, Cary, NC, USA), and all $P$-values are two-sided with $P \leqslant 0.05$ considered as statistically significant.

\section{RESULTS}

During $\sim 2.5$ million person-years of follow-up time, 634 first diagnoses of melanoma and 1065 first diagnoses of SCC were confirmed, and 15159 first diagnoses of BCC were reported among 108578 women. The distribution of cumulative UV flux was similar across different categories of most of the inherent skin cancer risk factors, whereas cumulative UV flux was higher among participants living in areas with high UV indices $(\geqslant 7)$ in early life and among participants with rigorous physical activity (Table 1). The incidence of different skin cancers was variable across quintiles of cumulative UV flux (Table 2). The trend of increasing incidence of skin cancer with increasing UV flux was most apparent for SCC
( $1 \%$ cases in the lowest quintile vs $52 \%$ cases in the highest quintile) as compared with that for BCC (1\% cases in the lowest quintile $v s 34 \%$ cases in the highest quintile) or melanoma ( $14 \%$ cases in the lowest quintile $v s 27 \%$ cases in the highest quintile).

There was little difference between the age-adjusted HRs and multivariable HRs for skin cancers associated with quintiles of cumulative UV flux (Table 2). Compared with women in the highest quintile, the HRs for melanoma were not statistically significant for women in lower quintiles ( $P$ for trend $=0.77$ ). However, the trend in HRs from the highest quintile to the lowest quintile was statistically significant for both SCC and BCC ( $P$ for trend $<0.0001)$. Results from cubic spline regression suggest that SCC appeared to be most strongly associated with increasing cumulative UV flux when compared with melanoma or BCC (Supplementary Figure S1). Analyses using cumulative UV flux as a continuous variable further suggest a more apparent increasing trend of SCC risk associated with cumulative UV flux (Table 2). The multivariable HRs per $200 \times 10^{-4} \mathrm{RB}$ units increase in cumulative UV flux were 0.979 (95\% CI: 0.933, 1.028) for melanoma, 1.072 (95\% CI: 1.041, 1.103) for SCC, and 1.043 (95\% CI: $1.034,1.052)$ for BCC. We explored the possible latent periods of exposure of 2-10 years, and found that the associations for different skin cancers with cumulative UV flux were generally consistent with the primary analyses (Table 3).

\section{DISCUSSION}

In the prospective cohort study of women residing across the United States, we demonstrated different associations of melanoma, SCC, and BCC with long-term UV exposure in adulthood, as measured by cumulative UV flux, a measure based on residential history. Our findings suggest that risk of SCC is more strongly associated with cumulative UV flux in adulthood than risks of BCC and melanoma. These results are unchanged after adjustment for a number of known skin cancer risk factors.

That sun exposure and geographic location are risk factors for the three most common types of skin cancer is well known; however, the nature of this relationship is most clearly established for BCC and SCC. This association is less clear in the case of melanoma, and evidence from case-control and descriptive studies both supports and refutes the association between geographic location/sun exposure and melanoma risk. For example, the absolute change in melanoma mortality for a $10 \%$ increase in UVB radiation among females in the United States decreased from 0.08 additional deaths per 100000 person-years in 1950-1959 to 0.01 additional deaths in 1990-1995 (Jemal et al, 2000). Another case-control study with 966 individuals found that lifetime sun exposure (assessed by total sun exposure hours using a Residence Work Calendar) was predominantly associated with an increased risk of SCC but a lower risk of melanoma (Kennedy et al, 2003). On the other hand, in an Australian study involving over 1000 melanoma cases based on population-based cancer registries in three states, the authors found that a decrease in latitude (related to an increase in sun exposure intensity) was associated with an increased incidence of melanoma (Green et al, 1996). Similar results on increased incident melanoma in geographic regions with decreased latitude have been reported among whites in a study using 43 population-based cancer registries in North America and Europe (Crombie, 1979) and in another study using 11 cancer registries in the United States (Eide and Weinstock, 2005). Evidence from a recent study using data from two independent case-control groups with a total of 197 melanoma cases also suggests that melanomas without signs of chronic sun-induced damage are more likely to occur on intermittently exposed body sites (e.g., trunk) rather than continuously exposed body sites 
Table 1. Distribution of cumulative UV flux $\left(\times 10^{-4} \mathrm{RB}\right.$ units) according to skin cancer risk factors

\section{No. of participants (\%) \\ Mean \pm s.d. \\ Range}

\section{Ability to tan after $2 \mathrm{~h}$ of sun exposure as a child}

\begin{tabular}{|c|c}
\hline Almost none & $7179(9)$ \\
Little tan & $18570(22)$ \\
Average $\tan$ & $37715(46)$ \\
Deep $\tan$ & $19383(23)$
\end{tabular}

$19383(23)$

$1643 \pm 1016$

$1652 \pm 1010$

$1676 \pm 1021$

$1692 \pm 103$
200-5362

200-5392

200-5340

$200-5370$

\section{Skin reaction after $2 \mathrm{~h}$ of sun exposure during childhood}

\begin{tabular}{|c|c}
\hline No burn & $16263(19)$ \\
Some redness & $36456(44)$ \\
Burn & $18671(22)$ \\
Painful burn & $7981(10)$ \\
Painful burn with blisters & $4425(5)$
\end{tabular}

$1692 \pm 1026$

$1679 \pm 1023$

$1651 \pm 1010$

$1658 \pm 1019$

$1647 \pm 1032$
$200-5362$

200-5370

200-5392

200-5296

200-5200

\section{Natural hair colour at age 20}

\section{Red}

Blonde

Light brown

Dark brown

Black

3519 (4)

$9792(12)$

32401 (39)

35480 (42)

2557 (3)
$1638 \pm 1021$

$1672 \pm 1034$

$1672 \pm 1021$

$1673 \pm 1017$

$1689 \pm 1036$
200-5130

200-5392

200-5362

200-5362

200-5370

\section{Moles count on the left arm}

\begin{tabular}{l|c}
$\begin{array}{l}\text { None } \\
1-2 \\
3-5\end{array}$ & $46214(63)$ \\
$\geqslant 6$ & $23781(32)$ \\
Lifetime severe sunburn counts & $1959(3)$ \\
None & $1488(2)$ \\
$1-2$ & $48293(63)$ \\
$3-5$ & $16310(21)$ \\
$\geqslant 6$ & $6309(8)$ \\
\end{tabular}

Family history of melanoma

No

No

$101972(94)$

6606 (6)

$1683 \pm 1025$

$1669 \pm 1020$

$1626 \pm 997$

$1641 \pm 1018$

$200-5370$

200-5328

200-5040

200-5296

\section{UV index at state of residence at birth}

\begin{tabular}{l|r}
$\leqslant 5$ & $24892(33)$ \\
6 & $42088(56)$
\end{tabular}

$\geqslant 7$

$7879(11)$

$1674 \pm 1020$

$1670 \pm 1019$

$1678 \pm 1027$

$1654 \pm 1023$

200-5392

$200-5296$

$200-5182$

200-5296

\section{UV index at state of residence at age 15}

\begin{tabular}{l|l}
$\leqslant 5$ & $24722(33)$ \\
6 & $42311(56)$
\end{tabular}

6
$\geqslant 7$

$7917(11)$

\section{UV index at state of residence at age 30}

\begin{tabular}{l|l}
$\leqslant 5$ & $20603(28)$ \\
6 & $41942(57)$
\end{tabular}

$\geqslant 7$

$41942(57)$

$10762(15)$

\section{Physical activity level}

$<3.0$ Metabolic equivalents hours per week

3.0-8.9 Metabolic equivalents hours per week

9.0-17.9 Metabolic equivalents hours per week

18.0-26.9 Metabolic equivalents hours per week

$\geqslant 27.0$ Metabolic equivalents hours per week

$20845(28)$
$20032(27)$
$14393(19)$
$7919(11)$
$11375(15)$

$682 \pm 1030$

$1664 \pm 1014$

200-5392

200-5362

\section{Rotating night shift}

\begin{tabular}{l|r} 
Never & $30775(41)$ \\
$1-9$ Years & $36222(48)$ \\
$\geqslant 10$ Years & $9048(12)$
\end{tabular}

Abbreviations: $\mathrm{RB}=$ Robertson-Berger; $\mathrm{UV}=$ ultraviolet.

\begin{tabular}{l|l}
$1636 \pm 970$ & $200-5296$ \\
$1626 \pm 973$ & $200-5362$ \\
$2098 \pm 1272$ & $200-5370$
\end{tabular}

$1630 \pm 965$
$1616 \pm 964$

$2144 \pm 1288$

200-5296

200-5362

200-5370

200-5296

200-5296

200-5370

$2163 \pm 1284$

200-5296

200-5362

200-5296

200-5296

200-5392

$1743 \pm 1025$
$1791 \pm 1023$

$1869 \pm 1032$

200-5296

200-5362

200-5296 
Table 2. Hazard ratios for melanoma, squamous cell carcinoma, and basal cell carcinoma according to cumulative UV flux

\begin{tabular}{|l|c|c|c|}
\hline & $\begin{array}{c}\text { No. of } \\
\text { cases } \\
(\%)\end{array}$ & $\begin{array}{c}\text { Age-adjusted } \\
\text { HR }(\mathbf{9 5 \% C l})\end{array}$ & $\begin{array}{c}\text { Multivariable HR } \\
(95 \% \mathrm{Cl})^{\mathbf{a}}\end{array}$ \\
\hline \multicolumn{3}{|c|}{ Melanoma (n=634 cases) } \\
\hline UV flux Q1 \\
UV flux Q2 & $88(14)$ & $0.66(0.30,1.47)$ & $0.85(0.36,2.01)$ \\
UV flux Q3 & $130(21)$ & $1.07(0.58,1.96)$ & $1.32(0.68,2.55)$ \\
UV flux Q4 & $112(18)$ & $0.89(0.56,1.41)$ & $1.02(0.63,1.67)$ \\
UV flux Q5 & $129(20)$ & $1.01(0.74,1.38)$ & $1.07(0.78,1.47)$ \\
P for trend & $175(28)$ & 1.00 & 1.00 \\
Per 200 $\times 10^{-4}$ & - & 0.68 & 0.77 \\
RB units & - & $1.004(0.966,1.044)$ & $0.979(0.933,1.028)$ \\
increase & & & \\
\hline
\end{tabular}

Squamous cell carcinoma ( $n=1065$ cases)

\begin{tabular}{|c|c|c|c|}
\hline UV flux $\mathrm{Q} 1^{\mathrm{b}}$ & $7(1)$ & $0.04(0.01,0.29)$ & $0.05(0.01,0.35)$ \\
\hline UV flux Q2 & $69(6)$ & $0.29(0.17,0.48)$ & $0.34(0.20,0.59)$ \\
\hline UV flux Q3 & $162(15)$ & $0.51(0.37,0.69)$ & $0.57(0.40,0.79)$ \\
\hline UV flux Q4 & $272(26)$ & $0.70(0.57,0.85)$ & $0.74(0.60,0.91)$ \\
\hline UV flux Q5 & $555(52)$ & 1.00 & 1.00 \\
\hline$P$ for trend & - & $<0.0001$ & $<0.0001$ \\
\hline $\begin{array}{l}\text { Per } 200 \times 10^{-4} \\
\text { RB units } \\
\text { increase }^{c}\end{array}$ & - & $1.069(1.046,1.092)$ & $1.072(1.041,1.103)$ \\
\hline
\end{tabular}

Basal cell carcinoma ( $n=15159$ cases)

\begin{tabular}{|l|c|c|c|}
\hline UV flux Q1 & $152(1)$ & $0.41(0.33,0.52)$ & $0.47(0.37,0.59)$ \\
UV flux Q2 & $2640(17)$ & $0.40(0.36,0.44)$ & $0.45(0.40,0.51)$ \\
UV flux Q3 & $3505(23)$ & $0.59(0.54,0.64)$ & $0.64(0.58,0.70)$ \\
UV flux Q4 & $3819(25)$ & $0.81(0.76,0.85)$ & $0.84(0.79,0.89)$ \\
UV flux Q5 & $5043(33)$ & 1.00 & 1.00 \\
P for trend & - & $<0.0001$ & $<0.0001$ \\
Per 200 $1^{-4}$ & - & $1.052(1.045,1.059)$ & $1.043(1.034,1.052)$ \\
RB units & & & \\
increasec & & & \\
\hline
\end{tabular}

Abbreviations: $\mathrm{Cl}=$ confidence interval; $\mathrm{HR}=$ hazard ratio; $\mathrm{UV}=$ ultraviolet.

${ }^{a}$ Multivariable analyses adjusted for age, susceptibility to burn, ability to tan, natural hair colour at age 20, number of moles on left arm, family history of melanoma, severe sunburn counts, UV indices at state of residence at birth, 15 and 30 years of age, physical activity level, and rotating night shift.

bUV flux quintiles: Q1 $=200-656, Q 2=678-1294, Q 3=1296-1872, Q 4=1874-2614$, and $\mathrm{Q} 5=2616-5392 \times 10^{-4} \mathrm{RB}$ units, respectively.

${ }^{c}$ Cumulative UV flux was modelled as a continuous variable in the models.

(e.g., face) (Landi et al, 2006). Another meta-analysis using data from 57 original case-control, cohort, or cross-sectional studies also supports the hypothesis that there is a positive association for intermittent sun exposure and an inverse association for a highly continuous pattern of sun exposure with regard to melanoma risk (Gandini et al, 2005). Overall, these findings support the hypothesis that melanoma is associated with intermittent UV exposure rather than cumulative UV exposure. If this is correct, it may explain why we did not observe clear or consistent evidence of a positive association between melanoma and cumulative UV flux in our study population.

A major strength of this study is the ability to simultaneously evaluate the risks of BCC, SCC, and melanoma in the same cohort of women. The NHS provides an excellent opportunity to study a population across the United States with high rates of follow-up. In addition, we were able to adjust for a number of other skin cancer risk factors, including sun exposure-related behaviours (i.e., physical activity level and rotating night shift) based on detailed follow-up information.
One limitation of this study is the generalisability of these results to other populations in the United States, including men. Previous studies have reported evidence suggesting heterogeneous effects of sun exposure for men and women. In a previous case-control study with 176 skin cancer cases and 216 controls, lifetime sun exposure (derived by summing the total hours spent outdoors at work, sports, recreation, or yard work in direct sunlight) was more strongly associated with SCC risk in women, whereas early-age (age 15-24) sun exposure was more relevant to SCC risk in men (Chen et al, 2010). Another case-control study with 718 melanoma cases and 945 controls also found a stronger association of melanoma risk with increasing UV flux in men than that in women (Fears et al, 2002). Also the north-south gradient in melanoma risk has been demonstrated to be more apparent for men than that for women in New Zealand (Bulliard et al, 1994; Bulliard, 2000). Further studies are needed to clarify whether the observed associations between cumulative UV flux and three types of skin cancer exist for men.

A potential limitation of using UV flux levels measured in RB metres includes the fact that these measurements are estimates of real values of UV irradiation and do not take into account variables such as the amount of time spent in the sun and use of sunscreens or clothing. Therefore, the exposure may be subject to measurement error and misclassified; although, such misclassification is likely to be non-differential and attenuate the risk estimates. In addition, there is no significant interaction between cumulative UV flux and individual behaviours (i.e., physical activity level and rotating night shift) related to sun exposure, and analyses stratified by sun exposure-related behaviours revealed little difference in associations of cumulative UV flux with risk of skin cancers across different behaviour categories (data available upon request). These results suggest that cumulative UV flux based on residential history may be used as a relatively reliable surrogate of UV exposure over long durations. Another issue is that RB metres are temperature sensitive (Johnsen and Moan, 1991). However, the overall influence of temperature on $\mathrm{RB}$ counts is relatively small as demonstrated in a previous study, which found that the difference in average summer temperatures for Oslo city in the period from 1951 to 1989 would influence annual RB counts in a similar manner as an about $2 \%$ change in the total amount of atmospheric ozone (Johnsen and Moan, 1991). Finally, cumulative UV flux in adulthood does not account for sun exposure in early life, a period when exposure may also be important for associated skin cancer risk in adulthood (Whiteman et al, 2001; Iannacone et al, 2012). Although we adjusted for several potential confounders related to early-life sun exposure (i.e., UV indices at state of residence at birth, 15 and 30 years of age) in the multivariable analyses, our results may still need to be interpreted with caution.

In summary, we evaluated the associations of long-term UV exposure and risk of three types of skin cancer in a cohort of women in the United States, and found differences in risks of different skin cancers associated with cumulative UV flux over long durations in adulthood, a measure that was estimated taking residential history into account. We found that the risk of incident SCC was positively associated with cumulative UV flux in adulthood. A similar but less pronounced trend was seen for BCC. In contrast, incident melanoma risk was not significantly associated with cumulative UV flux. These dose-response relations remained the same after adjusting for other skin cancer risk factors. Previous findings from this cohort suggest that sun exposure intensity in early life may increase the risk of skin cancer in adulthood (Qureshi et al, 2008). Results from the present study provide further evidence that the quantity of sun exposure received over long durations in adulthood as indicated by cumulative UV flux may also increase the risk of skin cancer, particularly for SCC. The differences in risks of incident SCC, BCC, and melanoma as related to UV exposure history suggest a variable role of UV 
Table 3. Multivariable hazard ratios ${ }^{\text {a }}$ for melanoma, squamous cell carcinoma, and basal cell carcinoma with lags of 2-10 years between exposure and outcome

\begin{tabular}{|c|c|c|c|c|c|c|c|c|c|c|}
\hline & \multicolumn{2}{|c|}{ 2- year lag } & \multicolumn{2}{|c|}{ 4- year lagc } & \multicolumn{2}{|c|}{ 6-year lag ${ }^{d}$} & \multicolumn{2}{|c|}{8 -year $\operatorname{lag}^{e}$} & \multicolumn{2}{|c|}{ 10-year lag ${ }^{f}$} \\
\hline & $\begin{array}{c}\text { No. of } \\
\text { cases }\end{array}$ & $\begin{array}{l}\text { Multivariable } \\
\text { HR }(95 \% \mathrm{Cl})\end{array}$ & $\begin{array}{l}\text { No. of } \\
\text { cases }\end{array}$ & $\begin{array}{l}\text { Multivariable } \\
\text { HR }(95 \% \mathrm{Cl})\end{array}$ & $\begin{array}{c}\text { No. of } \\
\text { cases }\end{array}$ & $\begin{array}{l}\text { Multivariable } \\
\text { HR }(95 \% \mathrm{Cl})\end{array}$ & $\begin{array}{c}\text { No. of } \\
\text { cases }\end{array}$ & $\begin{array}{l}\text { Multivariable } \\
\text { HR }(95 \% \mathrm{Cl})\end{array}$ & $\begin{array}{l}\text { No. of } \\
\text { cases }\end{array}$ & $\begin{array}{c}\text { Multivariable HR } \\
(95 \% \mathrm{Cl})\end{array}$ \\
\hline \multicolumn{11}{|l|}{ Melanoma } \\
\hline $\begin{array}{l}\text { UV flux Q1 } \\
\text { UV flux Q2 } \\
\text { UV flux Q3 } \\
\text { UV flux Q4 } \\
\text { UV flux Q5 } \\
P \text { for trend }\end{array}$ & $\begin{array}{r}95 \\
110 \\
101 \\
122 \\
167\end{array}$ & $\begin{array}{c}0.47(0.19,1.19) \\
0.64(0.30,1.34) \\
0.68(0.41,1.15) \\
0.91(0.66,1.25) \\
1.00 \\
0.14\end{array}$ & $\begin{array}{r}99 \\
102 \\
84 \\
132 \\
139\end{array}$ & $\begin{array}{c}0.96(0.38,2.42) \\
0.97(0.47,1.99) \\
0.84(0.48,1.46) \\
0.92(0.66,1.30) \\
1.00 \\
0.74\end{array}$ & $\begin{array}{r}81 \\
96 \\
76 \\
120 \\
131\end{array}$ & \begin{tabular}{|c|}
$0.62(0.19,2.04)$ \\
$0.83(0.36,1.96)$ \\
$0.76(0.43,1.36)$ \\
$0.91(0.63,1.30)$ \\
1.00 \\
0.40
\end{tabular} & $\begin{array}{r}84 \\
78 \\
66 \\
115 \\
119\end{array}$ & \begin{tabular}{|c|}
$0.50(0.16,1.55)$ \\
$0.62(0.27,1.45)$ \\
$0.72(0.39,1.34)$ \\
$0.82(0.58,1.18)$ \\
1.00 \\
0.19
\end{tabular} & $\begin{array}{r}72 \\
65 \\
62 \\
109 \\
106\end{array}$ & $\begin{array}{c}0.93(0.33,2.59) \\
0.66(0.29,1.50) \\
0.81(0.45,1.43) \\
0.90(0.62,1.30) \\
1.00 \\
0.61\end{array}$ \\
\hline \multicolumn{11}{|c|}{ Squamous cell carcinoma } \\
\hline $\begin{array}{l}\text { UV flux Q1 } \\
\text { UV flux Q2 } \\
\text { UV flux Q3 } \\
\text { UV flux Q4 } \\
\text { UV flux Q5 } \\
P \text { for trend }\end{array}$ & $\begin{array}{r}13 \\
91 \\
174 \\
264 \\
518\end{array}$ & $\begin{array}{c}0.12(0.05,0.31) \\
0.34(0.20,0.59) \\
0.64(0.45,0.90) \\
0.78(0.63,0.96) \\
1.00 \\
0.0004\end{array}$ & $\begin{array}{r}44 \\
102 \\
165 \\
287 \\
460\end{array}$ & $\begin{array}{c}0.51(0.23,1.12) \\
0.51(0.30,0.87) \\
0.67(0.47,0.94) \\
0.87(0.70,1.09) \\
1.00 \\
0.02\end{array}$ & \begin{tabular}{r|}
66 \\
112 \\
174 \\
257 \\
440
\end{tabular} & \begin{tabular}{|c|}
$0.57(0.21,1.55)$ \\
$0.60(0.33,1.07)$ \\
$0.72(0.51,1.01)$ \\
$0.87(0.69,1.09)$ \\
1.00 \\
0.05
\end{tabular} & $\begin{array}{r}83 \\
114 \\
168 \\
248 \\
407\end{array}$ & \begin{tabular}{|c|}
$0.22(0.10,0.49)$ \\
$0.43(0.25,0.75)$ \\
$0.40(0.40,0.82)$ \\
$0.72(0.58,0.89)$ \\
1.00 \\
0.0002
\end{tabular} & $\begin{array}{r}88 \\
119 \\
165 \\
230 \\
373\end{array}$ & $\begin{array}{c}0.62(0.30,1.29) \\
0.57(0.35,0.92) \\
0.73(0.52,1.03) \\
0.76(0.60,0.95) \\
1.00 \\
0.01\end{array}$ \\
\hline \multicolumn{11}{|c|}{ Basal cell carcinoma } \\
\hline $\begin{array}{l}\text { UV flux Q1 } \\
\text { UV flux Q2 } \\
\text { UV flux Q3 } \\
\text { UV flux Q4 } \\
\text { UV flux Q5 } \\
P \text { for trend }\end{array}$ & $\begin{array}{r}885 \\
2882 \\
3293 \\
3487 \\
4612\end{array}$ & $\begin{array}{c}0.50(0.42,0.60) \\
0.57(0.50,0.66) \\
0.79(0.72,0.86) \\
0.90(0.85,0.96) \\
1.00 \\
<0.0001\end{array}$ & $\begin{array}{l}1921 \\
2761 \\
2838 \\
3501 \\
4137\end{array}$ & $\begin{array}{c}0.42(0.35,0.49) \\
0.55(0.48,0.63) \\
0.74(0.67,0.81) \\
0.84(0.79,0.90) \\
1.00 \\
<0.0001\end{array}$ & $\begin{array}{l}2650 \\
2457 \\
2779 \\
2993 \\
3891\end{array}$ & \begin{tabular}{|c|}
$0.36(0.29,0.44)$ \\
$0.53(0.46,0.61)$ \\
$0.77(0.70,0.85)$ \\
$0.85(0.80,0.91)$ \\
1.00 \\
$<0.0001$
\end{tabular} & $\begin{array}{l}2204 \\
2295 \\
2367 \\
2824 \\
3472\end{array}$ & \begin{tabular}{|c|}
$0.39(0.32,0.48)$ \\
$0.59(0.51,0.68)$ \\
$0.77(0.69,0.85)$ \\
$0.86(0.80,0.92)$ \\
1.00 \\
$<0.0001$
\end{tabular} & $\begin{array}{l}1743 \\
2311 \\
2102 \\
2574 \\
3092\end{array}$ & $\begin{array}{c}0.65(0.54,0.78) \\
0.82(0.71,0.94) \\
0.87(0.79,0.97) \\
0.95(0.88,1.02) \\
1.00 \\
0.0001\end{array}$ \\
\hline \multicolumn{11}{|c|}{ 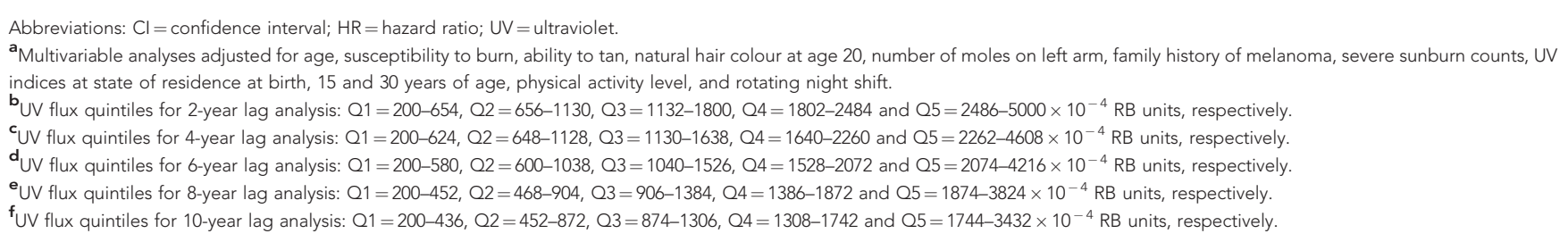 } \\
\hline
\end{tabular}

radiation in the carcinogenesis of the three major skin cancers. Considering the multiple effects of UV radiation has in the cutaneous tissue, including DNA damage, immune-suppression, and vitamin D production (Norval et al, 2011), additional work is needed to improve our understanding of the role that UV radiation has in the pathophysiology of the three major types of skin cancer.

\section{ACKNOWLEDGEMENTS}

We are indebted to the participants and staff of the Nurses' Health Study for their dedication and commitment. We thank all the state cancer registries in the United States for their help. This work was partly supported by National Institutes of Health, grants CA137365, CA10897 and CA87969.

\section{REFERENCES}

Almahroos M, Kurban AK (2004) Ultraviolet carcinogenesis in nonmelanoma skin cancer. Part I: incidence rates in relation to geographic locations and in migrant populations. Skinmed 3: 29-35, quiz35-36.

Arkema EV, Hart JE, Bertrand KA, Laden F, Grodstein F, Rosner BA, Karlson EW, Costenbader KH (2013) Exposure to ultraviolet-B and risk of developing rheumatoid arthritis among women in the Nurses' Health Study. Ann Rheum Dis 72: 506-511.
Blunden A, Lower T, Slevin T (2004) Knowledge, awareness, and use of the UV index amongst the West Australian public. J Health Commun 9: 207-221.

Boni R, Schuster C, Nehrhoff B, Burg G (2002) Epidemiology of skin cancer. Neuroendocrinol Lett 23(Suppl 2): 48-51.

Brooks KR, Brooks DR, Hufford D, Samenow J, Geller AC (2005) Are television stations and weather pages still reporting the UV index? A national media follow-up study. Arch Dermatol 141: 526.

Bulliard JL, Cox B, Elwood JM (1994) Latitude gradients in melanoma incidence and mortality in the non-Maori population of New Zealand. Cancer Causes Control 5: 234-240.

Bulliard JL (2000) Site-specific risk of cutaneous malignant melanoma and pattern of sun exposure in New Zealand. Int J Cancer 85: 627-632.

Chen YC, Christiani DC, Su HJ, Hsueh YM, Smith TJ, Ryan LM, Chao SC, Lee JY, Guo YL (2010) Early-life or lifetime sun exposure, sun reaction, and the risk of squamous cell carcinoma in an Asian population. Cancer Causes Control 21: 771-776.

Coldiron BM (1998) The UV Index: a weather report for skin. Clin Dermatol 16: $441-446$.

Colditz GA, Martin P, Stampfer MJ, Willett WC, Sampson L, Rosner B, Hennekens CH, Speizer FE (1986) Validation of questionnaire information on risk factors and disease outcomes in a prospective cohort study of women. Am J Epidemiol 123: 894-900.

Crombie IK (1979) Variation of melanoma incidence with latitude in North America and Europe. Br J Cancer 40: 774-781.

DeLuisi JJ, Harris JM (1983) A determination of the absolute radiant energy of a Robertson-Berger meter sunburn unit. Atmos Environ 17: 751-758.

Durrleman S, Simon R (1989) Flexible regression models with cubic splines. Stat Med 8: 551-561. 
Eide MJ, Weinstock MA (2005) Association of UV index, latitude, and melanoma incidence in nonwhite populations-US Surveillance, Epidemiology, and End Results (SEER) Program, 1992 to 2001. Arch Dermatol 141: 477-481.

Elder DE (1995) Skin cancer. Melanoma and other specific nonmelanoma skin cancers. Cancer 75(1 Suppl): 245-256.

English DR, Armstrong BK, Kricker A, Winter MG, Heenan PJ, Randell PL (1998) Case-control study of sun exposure and squamous cell carcinoma of the skin. Int J Cancer 77: 347-353.

Fears TR, Bird CC, Dt Guerry, Sagebiel RW, Gail MH, Elder DE, Halpern A, Holly EA, Hartge P, Tucker MA (2002) Average midrange ultraviolet radiation flux and time outdoors predict melanoma risk. Cancer Res 62: 3992-3996.

Gandini S, Sera F, Cattaruzza MS, Pasquini P, Picconi O, Boyle P, Melchi CF (2005) Meta-analysis of risk factors for cutaneous melanoma: II. Sun exposure. Eur J Cancer 41: 45-60.

Giovannucci E, Egan KM, Hunter DJ, Stampfer MJ, Colditz GA, Willett WC, Speizer FE (1995) Aspirin and the risk of colorectal cancer in women. $N$ Engl J Med 333: 609-614.

Green A, McCredie M, Giles G, Jackman L (1996) Occurrence of melanomas on the upper and lower limbs in eastern Australia. Melanoma Res 6: 387-394.

Hunter DJ, Colditz GA, Stampfer MJ, Rosner B, Willett WC, Speizer FE (1992) Diet and risk of basal cell carcinoma of the skin in a prospective cohort of women. Ann Epidemiol 2(3): 231-239.

Iannacone MR, Wang W, Stockwell HG, O'Rourke K, Giuliano AR, Sondak VK, Messina JL, Roetzheim RG, Cherpelis BS, Fenske NA, Rollison DE (2012) Patterns and timing of sunlight exposure and risk of basal cell and squamous cell carcinomas of the skin-a case-control study. BMC Cancer 12: 417.

IARC (2006) Exposure to artificial UV radiation and skin cancer. Available http://www.iarc.fr/en/publications/pdfs-online/wrk/wrk1/Artificial UVRad\&SkinCancer.pdf (accessed on 26 April 2013).

Jemal A, Devesa SS, Fears TR, Hartge P (2000) Cancer surveillance series: changing patterns of cutaneous malignant melanoma mortality rates among whites in the United States. J Natl Cancer Inst 92: 811-818.

Johnsen B, Moan J (1991) The temperature sensitivity of the Robertson-Berger sunburn meter, model 500. J Photochem Photobiol B 11(3-4): 277-284.

Kennedy C, Bajdik CD, Willemze R, De Gruijl FR, Bouwes Bavinck JN. Leiden Skin Cancer S (2003) The influence of painful sunburns and lifetime sun exposure on the risk of actinic keratoses, seborrheic warts, melanocytic nevi, atypical nevi, and skin cancer. J Invest Dermatol 120: 1087-1093.

Landi MT, Bauer J, Pfeiffer RM, Elder DE, Hulley B, Minghetti P, Calista D, Kanetsky PA, Pinkel D, Bastian BC (2006) MC1R germline variants confer risk for BRAF -mutant melanoma. Science 313: 521-522.

Lee TK, MacArthur AC, Gallagher RP, Elwood MJ (2009) Occupational physical activity and risk of malignant melanoma: the Western Canada Melanoma Study. Melanoma Res 19(4): 260-266.

Leiter U, Garbe C (2008) Epidemiology of melanoma and nonmelanoma skin cancer-the role of sunlight. Adv Exp Med Biol 624: 89-103.
Magnus K (1991) The Nordic profile of skin cancer incidence. A comparative epidemiological study of the three main types of skin cancer. Int J Cancer 47: 12-19.

Norval M, Lucas RM, Cullen AP, de Gruijl FR, Longstreth J, Takizawa Y, van der Leun JC (2011) The human health effects of ozone depletion and interactions with climate change. Photochem Photobiol Sci 10(2): 199-225.

Qureshi AA, Laden F, Colditz GA, Hunter DJ (2008) Geographic variation and risk of skin cancer in US women. Differences between melanoma, squamous cell carcinoma, and basal cell carcinoma. Arch Intern Med 168: 501-507.

Qureshi AA, Zhang M, Han J (2011) Heterogeneity in host risk factors for incident melanoma and non-melanoma skin cancer in a cohort of US women. J Epidemiol 21: 197-203.

Ramos J, Villa J, Ruiz A, Armstrong R, Matta J (2004) UV dose determines key characteristics of nonmelanoma skin cancer. Cancer Epidemiol Biomarkers Prev 13: 2006-2011.

Schernhammer ES, Razavi P, Li TY, Qureshi AA, Han J (2011) Rotating night shifts and risk of skin cancer in the nurses' health study. J Natl Cancer Inst 103: 602-606.

Schmalwieser AW, Schauberger G, Janouch M, Nunez M, Koskela T, Berger D, Karamanian G (2005) Global forecast model to predict the daily dose of the solar erythemally effective UV radiation. Photochem Photobiol 81: $154-162$.

Scotto J, Cotton G, Urbach F, Berger D, Fears T (1988) Biologically effective ultraviolet radiation: surface measurements in the United States, 1974 to 1985. Science 239(4841 Pt 1): 762-764.

Scotto J, Fears TR, Fraumeni Jr JF (1996) Solar radiation. In: Cancer epidemiology and prevention, Schottenfeld D, Fraumeni Jr JF (eds). 2nd edn. pp 355-372. Oxford University Press: New York.

Scotto J, Fears TR (1987) The association of solar ultraviolet and skin melanoma incidence among caucasians in the United States. Cancer Invest 5: 275-283.

Suzuki T, Ueda M, Ogata K, Horikoshi T, Munakata N, Ichihashi M (1996) Doses of solar ultraviolet radiation correlate with skin cancer rates in Japan. Kobe J Med Sci 42: 375-388.

Tatalovich Z, Wilson JP, Mack T, Yan Y, Cockburn M (2006) The objective assessment of lifetime cumulative ultraviolet exposure for determining melanoma risk. J Photochem Photobiol B85: 198-204.

Urbach F (1991) Incidence of nonmelanoma skin cancer. Dermatol Clin 9: 751-755.

Whiteman DC, Whiteman CA, Green AC (2001) Childhood sun exposure as a risk factor for melanoma: a systematic review of epidemiologic studies. Cancer Causes Control 12(1): 69-82.

This work is published under the standard license to publish agreement. After 12 months the work will become freely available and the license terms will switch to a Creative Commons AttributionNonCommercial-Share Alike 3.0 Unported License.

Supplementary Information accompanies this paper on British Journal of Cancer website (http://www.nature.com/bjc) 